\title{
From a polar to a marine environment: has the changing Arctic led to a shift in aerosol light scattering properties?
}

\author{
Dominic Heslin-Rees $^{1,2}$, Maria Burgos ${ }^{1,2}$, Hans-Christen Hansson ${ }^{1,2}$, Radovan Krejci $^{1,2}$, Johan Ström ${ }^{1,2}$, \\ Peter Tunved $^{1,2}$, and Paul Zieger ${ }^{1,2}$ \\ ${ }^{1}$ Department of Environmental Science, Stockholm University, Stockholm, Sweden \\ ${ }^{2}$ Bolin Centre for Climate Research, Stockholm University, Stockholm, Sweden
}

Correspondence: Paul Zieger (paul.zieger@aces.su.se)

Received: 28 May 2020 - Discussion started: 18 June 2020

Revised: 23 September 2020 - Accepted: 30 September 2020 - Published: 13 November 2020

\begin{abstract}
The study of long-term trends in aerosol optical properties is an important task to understand the underlying aerosol processes influencing the change of climate. The Arctic, as the place where climate change manifests most, is an especially sensitive region of the world. Within this work, we use a unique long-term data record of key aerosol optical properties from the Zeppelin Observatory, Svalbard, to ask the question of whether the environmental changes of the last 2 decades in the Arctic are reflected in the observations. We perform a trend analysis of the measured particle light scattering and backscattering coefficients and the derived scattering Ångström exponent and hemispheric backscattering fraction. In contrast to previous studies, the effect of in-cloud scavenging and of potential sampling losses at the site are taken explicitly into account in the trend analysis. The analysis is combined with a back trajectory analysis and satellite-derived sea ice data to support the interpretation of the observed trends. We find that the optical properties of aerosol particles have undergone clear and significant changes in the past 2 decades. The scattering Ångström exponent exhibits statistically significant decreasing of between $-4.9 \% \mathrm{yr}^{-1}$ and $-6.5 \% \mathrm{yr}^{-1}$ (using wavelengths of $\lambda=450$ and $550 \mathrm{~nm}$ ), while the particle light scattering coefficient exhibits statistically significant increasing trends of between $2.6 \% \mathrm{yr}^{-1}$ and $2.9 \% \mathrm{yr}^{-1}$ (at a wavelength of $\lambda=550 \mathrm{~nm}$ ). The magnitudes of the trends vary depending on the season. These trends indicate a shift to an aerosol dominated more by coarse-mode particles, most likely the result of increases in the relative amount of sea spray aerosol. We show that changes in air mass circulation patterns, specifically an increase in air masses from the south-west, are re-
\end{abstract}

sponsible for the shift in aerosol optical properties, while the decrease of Arctic sea ice in the last 2 decades only had a marginal influence on the observed trends.

\section{Introduction}

The Arctic region is warming considerably faster than the global average, a phenomenon known as Arctic amplification. Svalbard, a Norwegian archipelago located between 74 and $81^{\circ} \mathrm{N}$, has experienced some of the greatest observed regional temperature increases throughout the past 3 decades (Nordli et al., 2014). The impacts of Arctic amplification can be observed in a multitude of parameters (Meredith et al., 2020), including most notably, reductions in Arctic summer sea ice (Perovich et al., 2018). Diminishing sea ice has been proposed as the leading mechanism to explain the sensitivity of the region in terms of enhanced sea surface temperature increases (Screen and Simmonds, 2010). However, numerous other mechanisms have been studied, including changes in cloud cover (Schweiger et al., 2008), transportation of heat from the mid-latitudes (Overland and Wang, 2016), increases in the total water vapour in the Arctic atmosphere (Park et al., 2015), and sulfate aerosol reductions in Europe (Navarro et al., 2016). The exact relative importance of each of them is debated (Dai et al., 2019; Serreze and Barry, 2011). Arctic amplification may be linked to mid-latitude weather (Cohen et al., 2014; Pithan et al., 2018), with increased Rossby wave amplitude (Francis et al., 2017) and the appearance of atmospheric circulation anomalies (Lee et al., 2015). Changes in air circulation patterns within the Svalbard region have been 
observed and linked to changes in the Arctic Oscillation; the changes include increased anticyclonic advection from the south during winter and from the north during summer (Maturilli and Kayser, 2017).

Aerosols exert a considerable influence on the Arctic climate (Willis et al., 2018). The IPCC (2013) reports that in combination with clouds, aerosols continue to contribute the largest uncertainty to our understanding of changes to the Earth's energy budget. Aerosols can influence the Earth's climate directly through aerosol-radiation interactions. Arctic aerosols have a net cooling effect on the region (Fyfe et al., 2013), whereby aerosol particles reflect shortwave radiation. With the significant decrease in sulfate aerosol in the past few decades (Quinn et al., 2007), research into aerosol pollution in the Arctic has been gaining renewed interest as a means of explaining the increased rate of warming within the Arctic region (Garrett and Verzella, 2008; Navarro et al., 2016). The small amount of solar radiation that the Arctic receives means the region is fairly sensitive to any perturbations in radiative fluxes (Valero et al., 1989). In addition, aerosol particles may act as a layer of light absorbing material over a highly reflective ice/snow surface (Sokolik et al., 2010). Changes in aerosol concentrations are also likely to have an impact on cloud condensation nuclei (CCN) concentrations, given the two are well correlated (Jung et al., 2018). The strong seasonal cycles in Arctic aerosol properties have been well documented (Ström et al., 2003; Tunved et al., 2013; Freud et al., 2017; Pandolfi et al., 2018; Schmeisser et al., 2018). Observations from in situ ground-based sites have helped to describe this annual cycle. The Zeppelin Observatory (ZEP), Svalbard, experiences a typical Arctic annual cycle; there are peaks in accumulation-mode concentrations in late spring and early winter (Freud et al., 2017) in accordance with the Arctic haze phenomenon. The appearance of the Arctic haze phenomenon is a result of the combined effects from the increased south-to-north transportation of aerosol and a decline in removal efficiency during northward transport (Shaw, 1995; Quinn et al., 2007). Summer, with more frequent cloudiness and low-intensity precipitation events within a retracted polar front, is nearly free of anthropogenic aerosol influence (Willis et al., 2018), with the exception of well-defined events related to biomass burning and forest fires (Warneke et al., 2009). Summertime experiences increased concentrations of smaller nucleation and Aitken-mode particles, formed in situ (Freud et al., 2017). The light scattering properties at ZEP have been shown to reflect these changes in aerosol composition, with a scattering peak in the late winter and early spring (Schmeisser et al., 2018; Pandolfi et al., 2018; Heintzenberg, 1982). In addition, optical properties at ZEP signal an aerosol composition composed of smaller aerosol in the spring and larger aerosol in the late summer. More details on the seasonality of in situ optical properties can be found in Pandolfi et al. (2018) and Schmeisser et al. (2018).
Long-term measurements are vital to understanding changes related to the Arctic and thus to the Earth's climate. There is a need for long-term measurements to help reduce the uncertainties surrounding the impacts of aerosol (Hansen et al., 1995). Ground-based in situ measurement sites offer the chance to examine the long-term trends associated with aerosol optical properties. However, there are numerous difficulties in maintaining continuous and long-term observations, leading to a shortage of multidecadal time series. It is, therefore, essential to use the available data sets to examine trends and research the underlying mechanisms behind changes in aerosol properties. Aerosol optical properties experience a high degree of natural variability at different temporal resolutions and therefore pose difficulties in determining the underlying long-term trends. Sites in polar regions exhibit the largest number of statistically significant positive trends in particle light scattering (Collaud Coen et al., 2013, 2020), with multiple Arctic sites experiencing alternating trend slopes based on the duration of the trend (most notably in Utqiagivik, formerly Barrow, Alaska). Interestingly, most Arctic sites do not reflect the overall decreasing trends in scattering coefficients observed throughout Europe and North America (Collaud Coen et al., 2020). Thus, it is important to study why these differences are present and the mechanisms underlying these trends. Exploring the reasons for these trends is a central topic of this study and separates it from most previous long-term trend analyses. This study further differs from Collaud Coen et al. (2020) in that a longer data set is used and that the data are prescreened with respect to ambient relative humidity. The trends in aerosol measurements cited in this study are all conducted under dry conditions, as opposed to ambient conditions. Dry conditions, where the relative humidity (RH) is controlled, help to minimise the effects of water uptake, known as hygroscopicity. It should be noted that the hygroscopic effect on particle light scattering is more pronounced in the Arctic, compared with measurements taken in other global regions (Zieger et al., 2010, 2013).

This study aims to show long-term trends in Arctic aerosol optical properties, in combination with back trajectory analysis and satellite-derived sea ice data, to help better understand the changing processes controlling the optical properties of Arctic aerosol. Connecting back trajectory data with aerosol optical measurements helps to assess the potential aerosol sources and types. Not only does this study explore long-term trends in aerosol optical data, but it provides an analysis of the mechanisms influencing these changes. The influence on Arctic aerosol of sea ice retreat remains poorly constrained (Willis et al., 2018). One particular motivation for this study concerns the retreat in Arctic summer sea ice, which has seen significant reductions throughout the same period. The retreat of Arctic sea ice has the potential to induce changes to the aerosol composition; model results suggest an increase in sea salt aerosol (SSA) emissions from the loss of summer ice (Struthers et al., 2011; Browse et al., 2014). The aims of 
this study are to answer the following two research questions: (a) at what rate have key aerosol optical properties changed at Svalbard, in the Arctic, during the last 2 decades? (b) Can changes in long-term aerosol optical properties be explained by meteorological parameters and/or changes in sea ice coverage?

\section{Materials and methods}

\subsection{Measurement site}

The study is conducted using aerosol optical data from the Zeppelin Observatory (ZEP), located at $78.91^{\circ} \mathrm{N}, 11.89^{\circ} \mathrm{E}$ at an altitude of $474 \mathrm{~m}$ a.s.l. on the western edge of the Norwegian archipelago, Svalbard. The station is part of the World Meteorological Organisation's (WMO) Global Atmosphere Watch (GAW) programme. The nearby research village NyÅlesund is located on the coast of Kongsfjorden, approximately $2 \mathrm{~km}$ away from ZEP. The remoteness and altitude of the observatory allow for it to measure pristine Arctic air with minimal contamination from local pollution whilst also being able to observe long-range transported pollution. The location of ZEP as an Arctic site is unique, given its proximity to European sources and closeness to the Arctic Ocean sea ice edge. The nearby sea at ZEP is open all year round. Due to its elevated location, its exposure to free-tropospheric air and cloudiness separates it from other Arctic sites (Freud et al., 2017).

\subsection{Nephelometer}

At ZEP, measurements of aerosol light scattering properties have been performed using an integrating nephelometer (TSI Inc., USA, model 3563) since May 1999, making it, next to Utqiagivik (formerly Barrow, Alaska) and Alert (Canada), one of the longest time series records in the Arctic. The nephelometer performs continuous measurements of the light scattering of aerosol particles at three wavelengths $(\lambda=450,550,700 \mathrm{~nm})$. The particle light scattering coefficient, $\sigma_{\mathrm{sp}}(\lambda)\left(\mathrm{m}^{-1}\right)$, and the hemispheric backscattering coefficient, $\sigma_{\mathrm{bsp}}(\lambda)\left(\mathrm{m}^{-1}\right)$, are recorded, without any need of knowing any information about size, composition, and the physical state of the light-scattering aerosol. $\mathrm{RH}$, temperature, and pressure sensors also provide accurate readings at either the sample inlet or outlet. The nephelometer is regularly calibrated using $\mathrm{CO}_{2}$ and particle-free air. The contribution of light scattering by air molecules (Rayleigh scattering) is automatically corrected for by regular zero measurements of particle free air, about every hour. Gaps in the data set are present, due to either instrumental failure, in which the measurements did not perform correctly or the instrument was away for servicing. The nephelometer is connected to a whole-air inlet which follows the guidelines of WMO/GAW for aerosol sampling (WMO, 2016), with similar characteristics as the inlet described by Weingartner et al. (1999). Due to the temperature difference between inside and outside the inlet and the additional heating of the inlet, no additional drying of the aerosol is needed. The aerosol is sampled at dry conditions with $\mathrm{RH}=7.0 \pm 4.9 \%$ (mean \pm standard deviation; SD) to maintain the GAW-recommended conditions of $\mathrm{RH}<40 \%$.

The observatory, housing the instrumentation, was demolished in 1999 and rebuilt and reopened at the same location in May 2000. The nephelometer itself has undergone repairs, and a change to its inlet was made in June 2011. Detailed logbooks during the initial years of the observatory are lacking, providing difficulties in the traceability of past operating procedures and calibration. However, the manual inspection of all data and the removal of periods with obvious malfunctioning of the instrument are performed. More details on the nephelometer data treatment are given below.

\subsection{Back trajectory analysis}

Air mass back trajectories are calculated every hour, with the air parcels arriving at the altitude of ZEP. The HYSPLIT model (Draxler and Hess, 1998) is used to perform the back trajectory calculations. The meteorological fields are obtained from NOAA; the period 1999-2004 uses the FNL archive, and 2005-2016 uses the Global Data Assimilation System (GDAS) (http://ready.arl.noaa.gov/archives.php, last access: 12 March 2019).

\subsection{Data treatment}

The hourly medians of aerosol optical properties, back trajectory, and ambient relative humidity data are temporally collocated. After the temporal collocation of the data set, approximately $52.8 \%$ and $60.4 \%$ of the quality-controlled hourly medians for $\sigma_{\mathrm{sp}}$ and $\sigma_{\mathrm{bsp}}(\lambda=550 \mathrm{~nm})$, respectively, are left of the original data set. The period of study is from 1999 to the end of 2016.

This section concerns the data processing of the following:

1. treatment of optical properties; cleaning and computing medians for $\sigma_{\mathrm{sp}}, \sigma_{\mathrm{bsp}}, \alpha$, and $b$;

2. use of station meteorology data;

3. back trajectory calculations; combining land type data and determining source regions.

\subsubsection{Treatment of optical properties}

The data are quality checked using similar procedures to Asmi et al. (2013), whereby if a change in the instrumental conditions is coincident with a clear change in the optical properties, the data of the changed period are not included. Most notably, obvious outliers are removed. When available, the information from logbooks is used to remove periods of known instrument failure. Data are selected such that the $\mathrm{RH}$ 
at the sample outlet never surpasses $40 \%$; this helps minimise the effects on $\sigma_{\mathrm{sp}}$ and $\sigma_{\mathrm{bsp}}$ from hygroscopic growth (see e.g. WMO, 2016). Hourly medians are calculated (see Fig. S1 in the Supplement). The particle light scattering coefficients are adjusted to standard temperature and pressure, using data from the in-built instrument sensors. Detection limits (Anderson et al., 1996) and the illumination and truncation error correction method by Anderson and Ogren (1998) are applied to the hourly medians, based on their respective wavelength and scattering type. The detection limits for $\sigma_{\mathrm{sp}}$ and $\sigma_{\mathrm{bsp}}(\lambda=550 \mathrm{~nm})$ are 0.37 and $0.24 \mathrm{Mm}^{-1}$ respectively and represent the linearly-interpolated estimations for a $1 \mathrm{~h}$ averaging time, based on Anderson et al. (1996). Small values for $\sigma_{\mathrm{sp}}$ are considered less reliable due to instrument noise at low aerosol loadings (Schmeisser et al., 2017), and studies often use a constant threshold; e.g. Schmeisser et al. (2017) consider $\sigma_{\mathrm{sp}}>1 \mathrm{Mm}^{-1}$. However, for this study, thresholds on particle light scattering coefficients are applied based on detection limits, so as to not bias the data and push the extensive values higher. Overall, the fractions of data removed in terms hourly averages are as follows: $31.1 \%$ for $\sigma_{\mathrm{sp}}(\lambda=450 \mathrm{~nm}), 26.1 \% \sigma_{\mathrm{sp}}(\lambda=550 \mathrm{~nm})$, and $39.4 \% \sigma_{\mathrm{bsp}}$ $(\lambda=550 \mathrm{~nm})$. Most of the years are not affected by missing data with the exception of the years 2003 and 2016, where $66.6 \%-67.0 \%$ and $67.9 \%-74.0 \%$ of data are excluded respectively.

This study focuses on key aerosol optical properties needed to describe the aerosol interaction with solar radiation; these properties are needed to accurately estimate the direct aerosol radiative forcing (Haywood and Shine, 1995). We refer to both extensive and intensive aerosol optical properties; the intensive parameters are calculated from extensive parameters and are thus independent of the amount of aerosol. The extensive parameters include scattering coefficients $\left(\sigma_{\mathrm{sp}}\right)$ and backscattering coefficients $\left(\sigma_{\mathrm{bsp}}\right)$, whilst the intensive parameters are the scattering Ångström exponent $(\alpha)$ and the hemispheric backscattering fraction $(b) . \lambda$ is omitted from the abbreviations, in subsequent sections, for simplicity; however, it should be noted that the above optical properties are dependent on $\lambda$.

The hemispheric backscattering fraction $b$ is defined as

$b(\lambda)=\frac{\sigma_{\mathrm{bsp}}(\lambda)}{\sigma_{\mathrm{sp}}(\lambda)}$,

where $\lambda$ denotes the wavelength, $\sigma_{\mathrm{bsp}}$ is the hemispheric backscattering coefficient, and $\sigma_{\mathrm{sp}}$ the particle light scattering coefficient.

The scattering Ångström exponent $\alpha$ describes the wavelength dependency of the particle light scattering coefficient and is defined as

$\alpha=-\frac{\ln \left(\sigma_{\mathrm{sp}, 1} / \sigma_{\mathrm{sp}, 2}\right)}{\ln \left(\lambda_{1} / \lambda_{2}\right)}$,

where $\sigma_{\mathrm{sp}, 1}$ and $\sigma_{\mathrm{sp}, 2}$ are the particle light scattering coefficients at wavelengths $\lambda_{1}$ and $\lambda_{2}$ respectively. $\alpha$ represents the wavelength dependency of particle light scattering. $\alpha$ is inversely proportional to the size of the aerosol; thus larger particles exhibit lower $\alpha$ values and vice versa.

From these data, Eqs. (1) and (2) are used to calculate $b$ and $\alpha$, respectively. $b$ is calculated based on the green (550 nm) wavelength, and $\alpha$ is computed from the blue $(450 \mathrm{~nm})$ and the green wavelengths, as the red channel of the nephelometer generally exhibits greater variability. However, it should be noted that the results do not change significantly if a fit over all three channels is being used.

Daily and seasonal medians are computed and used to assess the trends in aerosol optical properties. The seasons are defined based on calendar dates: winter (DecemberFebruary), spring (March-May), summer (June-August), and autumn (September-November). Daily medians are based on a minimum of 6-hourly data points (in keeping with a $25 \%$ threshold imposed by Collaud Coen et al., 2020). Daily medians reduce the noise related to very low aerosol loadings; any uncertainties in $\sigma_{\mathrm{sp}}$ and $\sigma_{\mathrm{bsp}}$ are more pronounced in the Arctic region and are further enhanced in the derived intensive properties, $b$ and $\alpha$. It should be noted that the light scattering properties at ZEP do not show any pronounced daily cycle (not shown).

\subsubsection{Relative humidity}

When the observatory is in the midst of a cloud, large water droplets taken in by the whole-air inlet may affect the collection efficiency of the inlet. In addition, particles in the surrounding air can be removed due to in-cloud scavenging. This study aims to take this into account, however, for heated whole-air inlets, inside-cloud situations should not affect the measurements significantly (Asmi et al., 2013). Hourly mean values of ambient RH are used as a proxy for the presence of clouds. The ambient RH for ZEP is acquired through EBAS (http://ebas.nilu.no/, last access: 7 January 2020). The ambient RH measurements are operated by the Norwegian Institute for Air Research, NILU, Atmosphere and Climate Department. The data are prescreened to remove periods during which ambient $\mathrm{RH}$ exceeded $95 \%$, whereby it is assumed that cloud conditions were present for some fraction of that hour. The measurements are therefore assumed to be of cloud-free conditions (see Fig. S2 in the Supplement). The chosen threshold is the point at which a significant drop in $\sigma_{\mathrm{sp}}$ is observed. The observatory has frequent inside-cloud situations, which can affect the aerosol optical measurements; approximately $10.9 \%$ of the optical data is removed as a result of high ambient RH values, with summer the most affected season; $\sim 21.0 \%$ is removed, as opposed to $\sim 5.9 \%$, $\sim 12.1 \%$, and $\sim 6.8 \%$ for spring, autumn, and winter, respectively. 


\subsubsection{Trajectory calculations}

Each back trajectory is $7 \mathrm{~d}$ in length; the number of days is chosen as a compromise between restricting the increasing uncertainties the further back in time they go and capturing the typical lifetime of the aerosol in the atmosphere, and with this the main source regions. The HYSPLIT back trajectories provide a detailed history of the air parcels, including changes in latitude, longitude, altitude, the height of the mixed layer (ML), precipitation, relative humidity, and temperature. The ML forms part of the planetary boundary layer (PBL); it is defined as the height at which substances, such as aerosol, can be vertically dispersed and well mixed (Seinfeld and Pandis, 2006). The back trajectories are classified as being above or below the ML height. In the interest of this study, only data points (time) for which the air parcels reside within the ML are considered to be influenced by surface sources and dominate the observed signal at ZEP.

Wind speed is a main driver to SSA production and thus highly pertinent to this study. The average wind speeds are calculated as part of the back trajectory analysis based on the change in latitude, longitude, and altitude of each respective hourly data point. The direction from which back trajectories arrive at ZEP is computed by calculating the mean Cartesiantransformed coordinates. The mean coordinate is used to assign each back trajectory a region, namely north-west (NW), north-east (NE), south-east (SE), and south-west (SW). The region the back trajectories are assigned is dependent on the average of the coordinates, so they are not defined based on the origin. It is understood that back trajectories can cross multiple regions; the assigned regions simplify the classification. The four regions are defined relative to ZEP being at the centre. Monthly Special Sensor Microwave/Imager (SSM/I) satellite-derived sea ice concentration (SIC) data from the Version 1.1 Hadley Centre Sea Ice (HadISST1.1) data set (Rayner et al., 2003) are used. The SIC data set is of a $1^{\circ} \times 1^{\circ}$ resolution. SIC data are temporally collocated with the back trajectories. Each data point from the back trajectory is classified into the following: (1) above ML, (2) above land and within ML, (3) above sea ice and within ML, and (4) above open water and within ML. The ice surface type is defined as having a mean SIC above 0.85 (see Fig. S3 in the Supplement), which is commonly used in the literature (e.g. Rayner et al., 2003; Fetterer et al., 2016; Stroeve and Meier, 2003), although lower thresholds have been used as well.

\subsection{Statistical tools for trend analysis}

For all the trend analyses, the Python scipy.stats package is used within SciPy (v.1.1.0) (Virtanen et al., 2020).

\subsubsection{Seasonal Mann-Kendall test}

The Mann-Kendall test (hereafter "MK test") is one of the most widely used non-parametric tests for determining the statistical significance of trends in environmental data. The test is rank-based with a null hypothesis that the time series has no trend. The alternative hypothesis is that a monotonic trend exists (Gilbert, 1987). The MK test is ideal since it is not affected by missing values. Given that the data set contains gaps and irregular spacing, this is a major advantage. Hirsch et al. (1982) developed the "seasonal" MK test to take seasonality into account. The seasonal MK test works by separating the data into distinct seasons and then comparing like for like.

The MK test assumes that the data are independent; thus there is no autocorrelation. Kulkarni and von Storch (1995) show that the result of the MK test depends strongly on the autocorrelation; a positive autocorrelation increases the likelihood that the null hypothesis is rejected when there is no trend. The time series is "pre-whitened" (PW) based on the trend-free pre-whitening (TFPW) procedure described in detail in Yue et al. (2002).

The daily medians provide a sufficient amount of data points; however, they are considerably more plagued by autocorrelation than time series constructed from longer averaging periods (i.e. seasonal medians). The seasonal MK test is performed on the PW daily medians with a two-tailed significance test of $95 \%$. Medians are used for all the analyses as the variables are non-normally distributed. Medians are also less affected by outliers.

\subsubsection{The Theil-Sen estimator}

The Theil-Sen estimator (TS) is used in this study to calculate the slope of the linear trends. The procedure developed by Sen (1968) is useful, as it is relatively less affected by outliers. TS is a non-parametric tool (therefore no type of distribution needs to be assumed for the data) and often accompanies the MK test. TS works by calculating the median of all the slopes of every pair of ordered data points. The slope is unbiased in regards to highly autocorrelated data; however standard errors are affected by autocorrelation. The estimated slopes of the regression lines are multiplied by 365.25 or 4 for daily and seasonal medians respectively. The relative trends (i.e. $\% \mathrm{yr}^{-1}$ ) are obtained by dividing by the median of the data set in question, similar to previous studies (e.g. Asmi et al., 2013).

\subsubsection{Least mean square analysis (LMS)}

The least mean square analysis (LMS) is applied to the logarithm of the dependent variable to calculate the relative trends. The logarithm approximates the data to a normal distribution, allowing for the use of this statistical tool.

$\log \left(X_{t}+s\right)=a+\beta \cdot t+\epsilon_{t}$,

where $X_{t}$ is the observation at time $t, a$ is the regression parameter representing the intercept, and $\beta$ is the regression 
parameter representing the slope, while $s$ is a small scalar. $\epsilon_{t}$ is the random error term associated with each observation.

The confidence level is set at $95 \%$, and the trend is deemed as having statistical significance (ss) if $\left|\beta / \mathrm{SE}_{\beta}\right|>1.960$, where $\mathrm{SE}_{\beta}$ denotes the standard error of the slope, $\beta$. For LMS trends not in terms of relative changes, the logarithm is not applied to $X_{t}$.

\section{Results}

Section 3.1 focuses on long-term trends; trends in aerosol light scattering properties are presented in Sect. 3.1.1, and the trends in key meteorological parameters from the back trajectory analysis and the changes in source types and regions are presented in Sect. 3.1.2. The trends are calculated and presented based on both seasonal and daily medians. The seasonality of the trends is also included. The final part of the results section, Sect. 3.2, combines the aerosol and back trajectory parameters.

\subsection{Trend analysis}

\subsubsection{Aerosol optical properties}

The long-term trends in $\sigma_{\mathrm{sp}}, \sigma_{\mathrm{bsp}}, b$, and $\alpha$ are presented in Fig. 1 based on the seasonal medians. $\sigma_{\mathrm{sp}}$ and $\sigma_{\mathrm{bsp}}$ both display increasing statistically significant trends estimated to be in the range of 0.05 and $0.01 \mathrm{Mm}^{-1} \mathrm{yr}^{-1}$ respectively. $\sigma_{\mathrm{sp}}$ and $\sigma_{\text {bsp }}$ show clear seasonality with higher scattering coefficients occurring in spring and winter. $b$ displays a nonstatistically significant decreasing trend of $-0.0002 \mathrm{yr}^{-1} . \alpha$, however, shows a large and decreasing statistically significant trend of approximately $-0.07 \mathrm{yr}^{-1} . \alpha$ is largest during the spring and summer, whilst autumn experiences the smallest medians. $b$ experiences a peak in summer and is at its lowest value in winter. The end of 2002 and the start of 2003 display relatively increased $\sigma_{\mathrm{sp}}$ and $\sigma_{\mathrm{bsp}}$ seasonal medians compared with medians either side. The seasons in question exhibit a decreased $\alpha$ value. Tunved et al. (2013) observed a reduced aerosol volume size distribution in 2002, which may explain the low $\alpha$ medians for these seasons. Furthermore, Eleftheriadis et al. (2009) show increased BC concentrations for 2003.

The trends based on seasonal and daily medians are displayed in the Supplement (see Tables S1-S4). It should be noted that the trends calculated based on daily medians exhibit reduced magnitudes. The removal of inside-cloud situations had a negligible effect on the overall trends (see Fig. S2 in the Supplement).

The trends for each season, using the MK and LMS methods, are examined in Fig. 2. The level of significance is set at $95 \%$ for both methods. The two statistical methods agree well with one another, except for $\sigma_{\mathrm{bsp}}$ and $b$ for which the LMS method presents reduced magnitudes for the trends; the increased frequency of low values amongst $\sigma_{\mathrm{bsp}}$ and $b$ is a likely explanation for the inconsistency. $\sigma_{\mathrm{sp}}$ and $\sigma_{\mathrm{bsp}}$ exhibit statistically significant increasing relative trends for all seasons except spring, with the most prominent trends during winter $\left(\sim 6.2 \% \mathrm{yr}^{-1}\right.$ to $6.5 \% \mathrm{yr}^{-1}$ and $\sim 1.9 \% \mathrm{yr}^{-1}$ to $5.3 \% \mathrm{yr}^{-1}$ for $\sigma_{\mathrm{sp}}$ and $\sigma_{\mathrm{bsp}}$, respectively). The overall trend in $\sigma_{\mathrm{sp}}$ is $\sim 2.6 \% \mathrm{yr}^{-1}$ to $2.9 \% \mathrm{yr}^{-1}$. $\sigma_{\mathrm{bsp}}$ displays a trend of $\sim 0.7 \% \mathrm{yr}^{-1}$ to $2.3 \% \mathrm{yr}^{-1}$. $\sigma_{\mathrm{sp}}$ and $\sigma_{\mathrm{bsp}}$ display a similar pattern in the magnitudes of the different seasons. $b$ displays a slight statistically significant decreasing trend during all seasons, except spring. The largest decreasing trends are in autumn $\left(-0.2 \% \mathrm{yr}^{-1}\right.$ to $\left.-0.9 \% \mathrm{yr}^{-1}\right)$ and winter $\left(-0.1 \% \mathrm{yr}^{-1}\right.$ to $\left.-0.7 \% \mathrm{yr}^{-1}\right) . \alpha$, however, exhibits statistically significant decreasing relative trends for all seasons. The most prominent seasonal trend for $\alpha$ is during autumn $\left(-7.2 \% \mathrm{yr}^{-1}\right.$ to $\left.-7.5 \% \mathrm{yr}^{-1}\right)$. Autumn and summer are the cleanest periods of the year at ZEP, and despite low concentrations during these periods, these seasons display the strongest trends in $\alpha$. The overall trend in $b$ is statistically significant and decreasing based, $\sim-0.07 \% \mathrm{yr}^{-1}$ to $-0.3 \% \mathrm{yr}^{-1} . \alpha$ displays an overall trend of $\sim-4.9 \% \mathrm{yr}^{-1}$ to $-6.5 \% \mathrm{yr}^{-1}$.

\subsubsection{Trajectory analysis}

The relative accumulated times back trajectories spend above each surface type are shown in Fig. 3a. The back trajectories spend approximately $34 \%$ of the time within the ML; however, this undergoes significant interannual variability. The relative contributions for open water, land, and ice are $17 \%$, $5 \%$, and $12 \%$ respectively. The contribution from open water increases over time and is much more apparent in the last few years. The contribution from land, by comparison, shows little long-term change throughout. Seasonal variability in the surface types is displayed; the winter and spring seasons are slightly more prominent for land, reflecting the expansion of the polar front. Furthermore, the time above ice is noticeably more reduced during summer and autumn months. Figure $3 b$ shows that the median wind speed of air parcels along the back trajectories and within the ML has increased slightly. The wind speeds have undergone an absolute increase of $\sim 0.62 \mathrm{~m} \mathrm{~s}^{-1}$ throughout the period in question. It is further noticeable that air parcels experience greater wind speeds during the winter, whilst the summer displays a reduction in wind speeds; this is in keeping with the retreat and advance of the polar front, allowing back trajectories to travel further. Figure $3 c$ details the relative contributions from the four specified regions, namely the NE, NW, $\mathrm{SE}$, and SW. In terms of changes in air circulation patterns, the back trajectories from the SW, most likely crossing over the Atlantic Ocean, make up an increasing proportion of the air masses arriving at ZEP. Both regions to the west have observed an increase in their relative contribution, whereas air masses predominantly arriving from the east have witnessed a reduction. The NE and SE made up the majority of air mass contributions (i.e. $\sim 37 \%$ and $33 \%$, respectively) at the start 

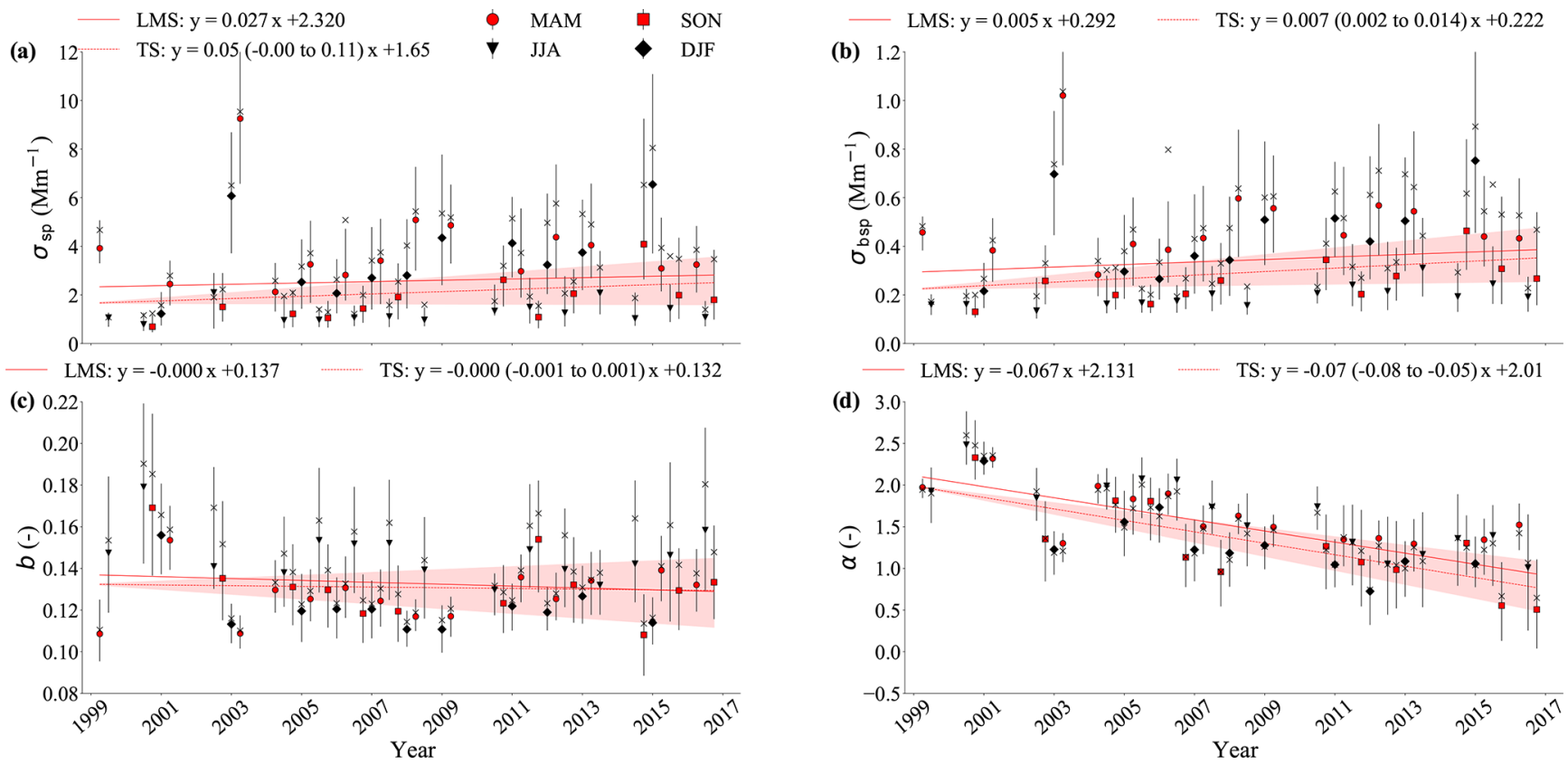

Figure 1. Long-term trends of the seasonal medians for (a) the particle light scattering coefficient $(\lambda=550 \mathrm{~nm})$, (b) the particle light backscattering coefficient $(\lambda=550 \mathrm{~nm})$, (c) the hemispheric backscattering fraction $(\lambda=550 \mathrm{~nm})$, and (d) the scattering Ångström exponent $\left(\lambda_{1}=450 \mathrm{~nm}, \lambda_{2}=550 \mathrm{~nm}\right)$. The seasonal medians are denoted by their respective symbols. The error bars denote the length of the $25 \mathrm{th}$ and 75 th percentile values. The seasonal mean is given by the cross. The solid and dashed red lines represent the least mean square (LMS) and Theil-Sen slope (TS) of the seasonal medians, respectively. The red shaded area denotes the associated $90 \%$ confidence interval of the TS slope. Note that TS is not used to test the statistical significance.
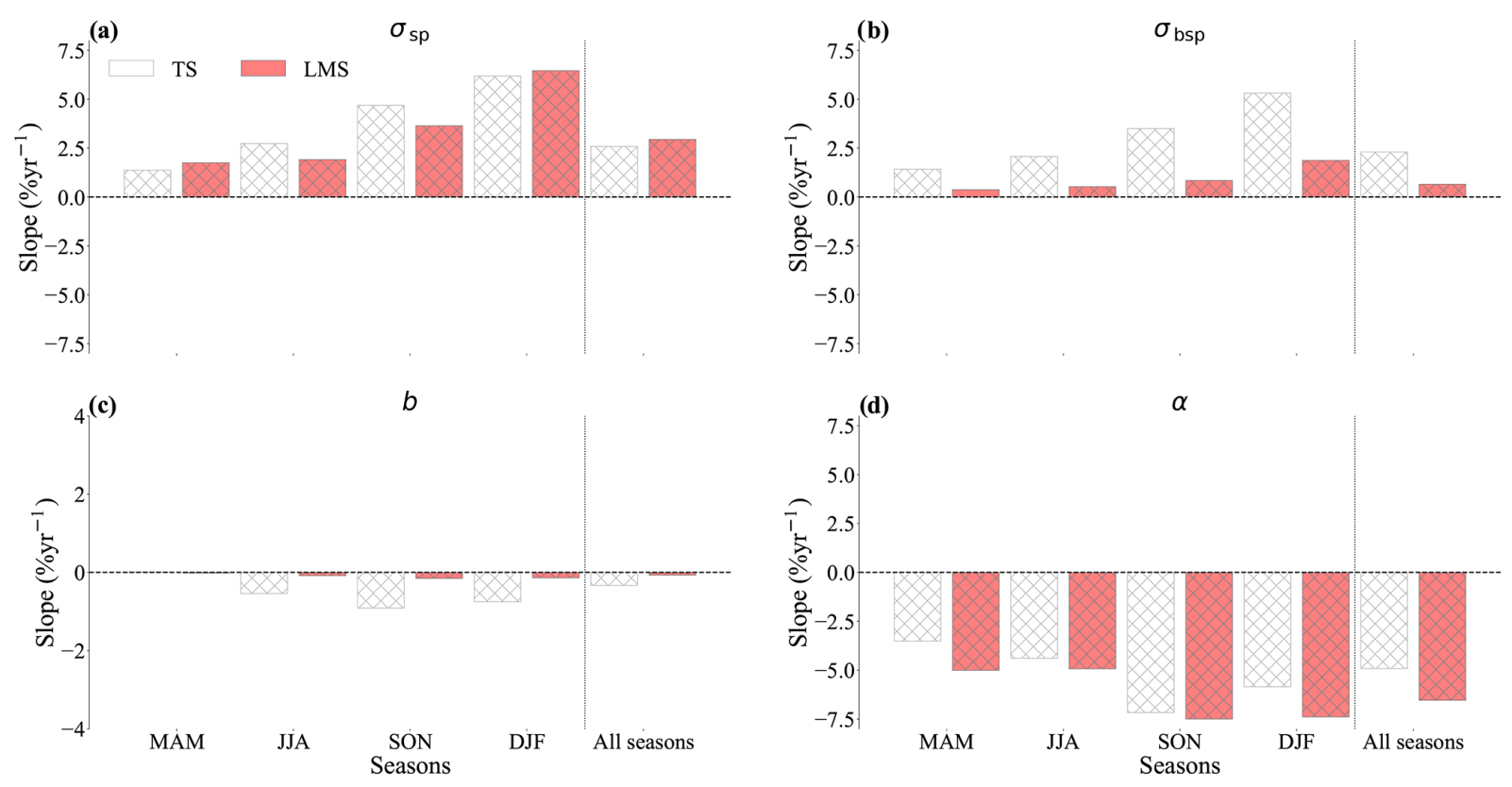

Figure 2. Relative trends based on daily medians for (a) the particle light scattering coefficient, (b) the particle light backscattering coefficient, (c) the hemispheric backscattering fraction (note the different $y$ scale), and (d) the scattering Ångström exponent for different and all seasons. The white bar displays the Theil-Sen estimator (TS). The red bar displays log-transformed least mean square (LMS) trends. Cross-hatching denotes trends that have statistical significance (ss) at a confidence interval of $95 \%$. The ss for the TS is based on the "pre-whitened" (PW) time series. The trends in their respective units $\mathrm{yr}^{-1}$ are in the tables in the Supplement. The dashed line aids the reader in separating the individual seasonal trends and the trend with all the seasons included. 
of the study period; however, the years towards the end of study period exhibit a more equal mix of air mass origins. There are noticeable peaks in the relative contribution from open water by season (signified by the dashed black line in Fig. 3a), coinciding with seasons experiencing greater contributions from the SW.

The relative trends, in terms of percentage increase, for back trajectory parameters based on daily medians are shown in Fig. 4. The time spent over open water and within the ML displays large statistically significant trends; in particular, spring and autumn show large positive relative changes $\left(3.3 \% \mathrm{yr}^{-1}\right.$ and $3.4 \% \mathrm{yr}^{-1}$ to $3.5 \% \mathrm{yr}^{-1}$, respectively), whilst spring shows a decreasing trend. The trends in wind speed are statistically significant for autumn and across all seasons but $<1 \% \mathrm{yr}^{-1}$. The trends in daily medians for open water and precipitation display similar patterns in their respective magnitudes amongst the different seasons.

Figure 5 displays the relative contributions from the four regions, namely the NE, NW, SE, and SW. Note that these relative trends are computed based on monthly contributions, due to the high presence of zero values in the daily values. The relative trends for air masses arriving from the west are noticeably large in magnitude, in particular the south-west. The south-west displays statistically significant increasing trends for autumn and across all seasons $\left(6.0 \% \mathrm{yr}^{-1}\right.$ to $6.7 \% \mathrm{yr}^{-1}$ and $2.6 \% \mathrm{yr}^{-1}$ to $3.2 \% \mathrm{yr}^{-1}$, respectively). The relative trends are decreasing for both the air masses arriving from the east. The north-east displays a large statistically significant decreasing trend in autumn. The relative trends for time spent over the open water (Fig. 4a) and the contribution from SW air masses (Fig. 5c) also display similar variations in the magnitudes for each season.

\subsection{Increased contribution from coarse-mode particles}

$\alpha$ is the only aerosol light scattering property featured in this part of the results as it shows the largest change of the last 2 decades. $\alpha$ is a qualitative indicator of aerosol particle size (Ångström, 1929), where $\alpha \leq 1$ indicates an aerosol size distribution dominated by coarse-mode particles.

The influence on $\alpha$ of the various surface types is displayed in the ternary plots (see Fig. 6). Each hexbin displays a unique combination of the different surface types, namely open water, land, and ice (all within the ML). The hexbin near the top vertex of each ternary plot displays the median $\alpha$ observed at ZEP when the arriving back trajectories spend nearly all of their time above land. It is apparent that back trajectories that traverse over a relatively large proportion of land show higher $\alpha$ values (more yellow). Descending the right edge (land) from the top vertex, the individual hexbins represent back trajectories that spend an increasing amount of time over open water. It is evident that the median $\alpha$ is lower (i.e. more blue) as the relative amount of time over open water increases (hexbins near to the lower right vertices in Fig. 6). For Fig. 6a, the relative residence times are potentially skewed by back trajectories that spend very little time within the ML. There is an additional requirement in Fig. $6 \mathrm{~b}$ to ensure that the back trajectories spend at least $40 \%$ of the $7 \mathrm{~d}$ within the ML. It is noticeable in Fig. $6 \mathrm{~b}$ that the number of data points is considerably lower for back trajectories that traversed mainly over land (see hexbins near to the top vertices in Fig. 6b), thus not meeting the required minimum number. Svalbard is an archipelago and some considerable distance from the main continental landmasses; thus it makes sense for back trajectories that are completely dominated by land not to be present. Overall, there is a clear gradient in $\alpha$ values, as the percent contribution from open water increases at the expense of land and ice. Moreover, this gradient is more pronounced as the amount of time back trajectories within the ML increases.

Figure 7 correlates the seasonal $\alpha$ medians observed throughout the 18 years with the relative contribution of the combined north-west and south-west air masses. The correlation is most striking for autumn, with an $r$ value (correlation coefficient) of -0.65 . Moreover, the influence of NW and SW air masses is largest in autumn. The variability in the contribution of NW and SW air masses for the different seasons is apparent; spring and winter show smaller contributions from NW and SW overall. Spring 2003 displays an increased contribution from NW and SW air masses of $~ 49 \%$ (compared with contributions in spring 2001 and 2004 of $\sim 32 \%$ and $17 \%$ ), providing a partial explanation for the seasonal low in $\alpha$.

\section{Discussion}

Table 1 presents an overview of the main findings. $\alpha$ decreases for all seasons, with a clear NW and SW increase throughout the year and slight decreases in NE and SE in the autumn and winter.

Increasing concentrations of coarse-mode particles relative to fine-mode particles reduce $\alpha$ (Schuster et al., 2006). Hence, the large decreasing trend in $\alpha$ (Fig. 1d) is suggestive of a significant shift to aerosol dominated more by coarsemode particles. At the same time, increasing trends in $\sigma_{\mathrm{sp}}$ and $\sigma_{\text {bsp }}$ are observed. Accumulation-mode particles are responsible for the majority of light scattering; however, as shown in Fig. S4 (in the Supplement) at ZEP coarse-mode particles still contribute a significant amount to the overall light scattering. The relative increase in coarse-mode particles can, therefore, explain the increasing trend in $\sigma_{\mathrm{sp}}$ (Fig. 1a) as well. Smaller particles, on the other hand, exhibit increased values in $b$ (Seinfeld and Pandis, 2006). $b$ is more sensitive to the changes to the distribution of particles at the smaller end of the accumulation mode (Collaud Coen et al., 2007). There is a small negative trend in $b$ (Fig. 4); nonetheless, a small relative decrease in $b$ could potentially mean substantial changes at the lower end of the accumulation mode. The trends reported are consistent in sign and significance with those in 

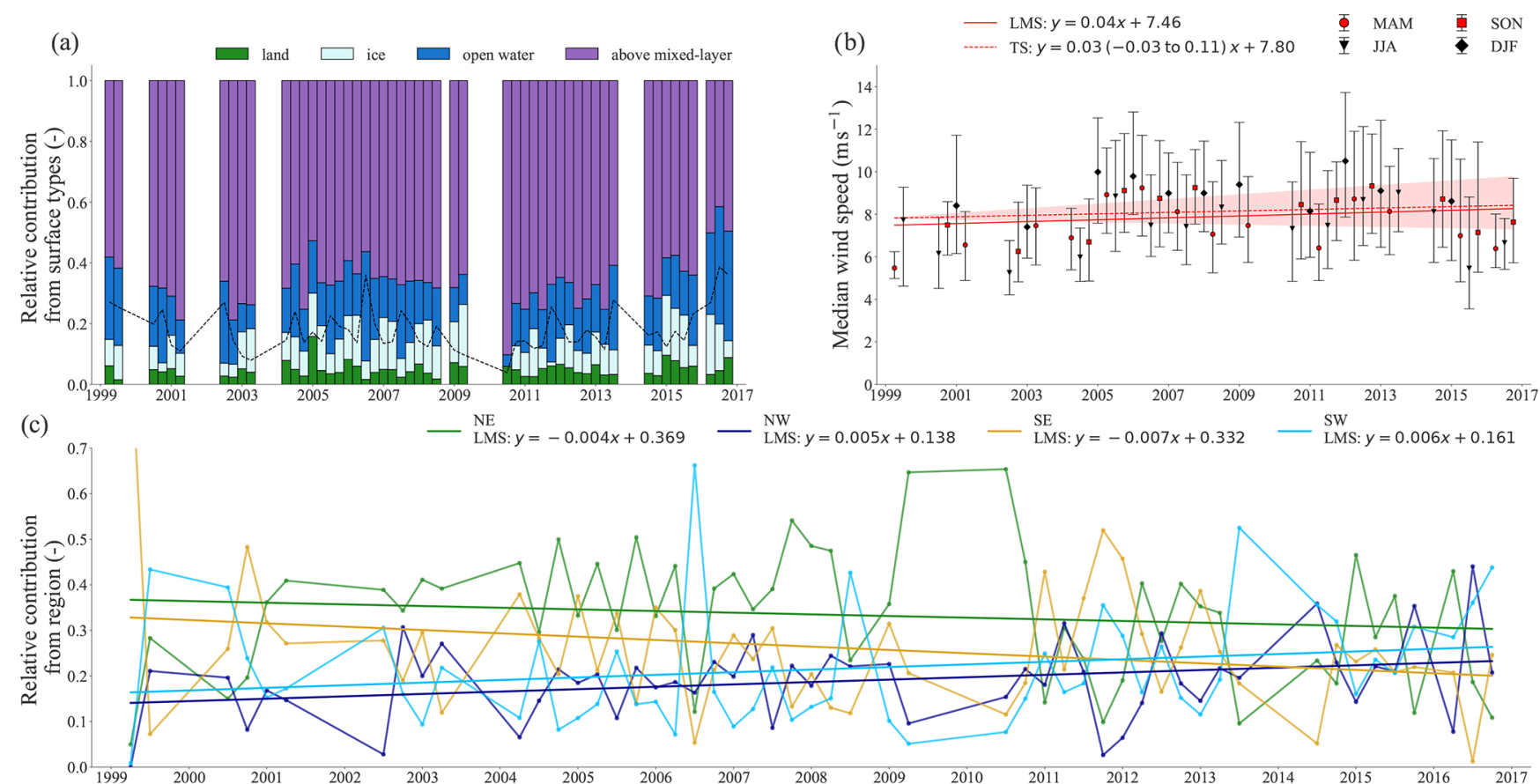

Figure 3. Long-term trends in (a) the relative contribution of the accumulated time per season air parcels spent above land, ice, and open water (whilst within the ML) and above the ML. (b) Median wind speed of air parcels located within the ML. (c) The relative contribution from the four different regions. The dashed black line in panel (a) presents the proportion of accumulated seasonal times for open water. For panel (b), the dashed red line represents the Theil-Sen slope (TS) of the seasonal medians. The error bars denote the length of the 25 th and 75th percentile values. The red shaded area denotes the associated $90 \%$ confidence interval of the TS slope. The solid lines in panels (b) and (c) display the least mean square (LMS) regression fit. Note the scale for the $y$ axis of panel (c) is reduced to 0.6, and the south-east contribution in spring 1999 is $\sim 94 \%$.
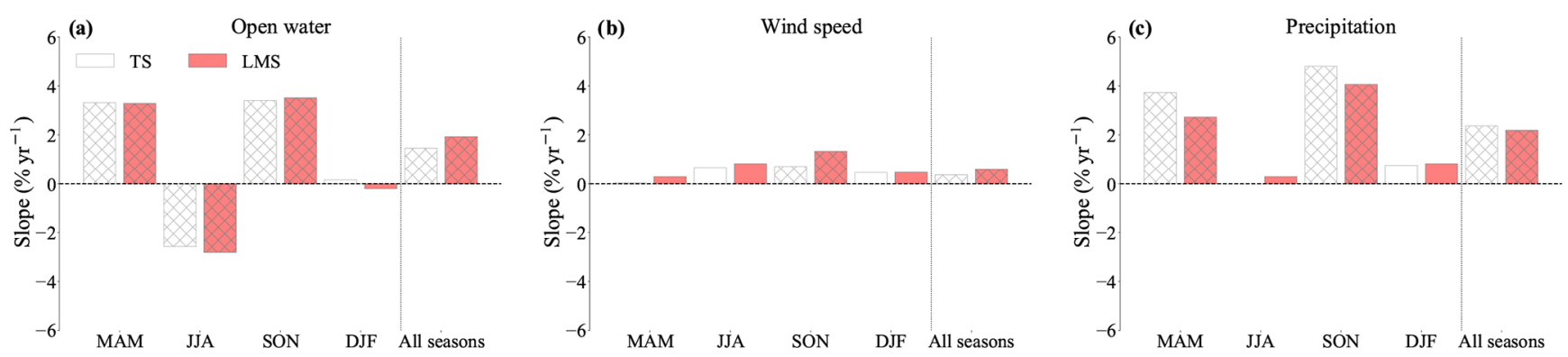

Figure 4. Relative trends in daily medians for (a) time spent above open water and within the ML, (b) median wind speed, and (c) accumulated precipitation along each back trajectory for different seasons and all seasons. The white bar displays the Theil-Sen estimator (TS). The red bar displays log-transformed least mean square (LMS) trends. Cross-hatching denotes trends that have statistical significance (ss) at a confidence interval of $95 \%$. The ss for the TS is based on the "pre-whitened" (PW) time series. The dashed line aids the reader in separating the individual seasonal trends and the trend with all the seasons included.

Collaud Coen et al. (2020). It should be mentioned though that gaps in the data could affect the calculated magnitude of the trends. Previous studies have used different averaging and pre-whitening methods to calculate the trends and their respective statistical significance (e.g. Pandolfi et al., 2018; Collaud Coen et al., 2013, 2020). However, by applying different statistical methods on both daily and seasonal averaging times, a better indication of the robustness of the derived trends is achieved.
Sea spray aerosol (SSA) is the most plausible type of coarse-mode aerosol to be encountered at ZEP. It is produced at the ocean surface through the process of wind-induced bubble bursting and the tearing of wave crests (O'Dowd and De Leeuw, 2007). The production and transportation of SSA are linked to surface wind speeds (De Leeuw et al., 2011), with increasing sea salt mass associated with increasing wind speeds (Lewis and Schwartz, 2004). SSA is identified by smaller $\alpha$ values, typically less than 0.5 (Schmeisser et al., 

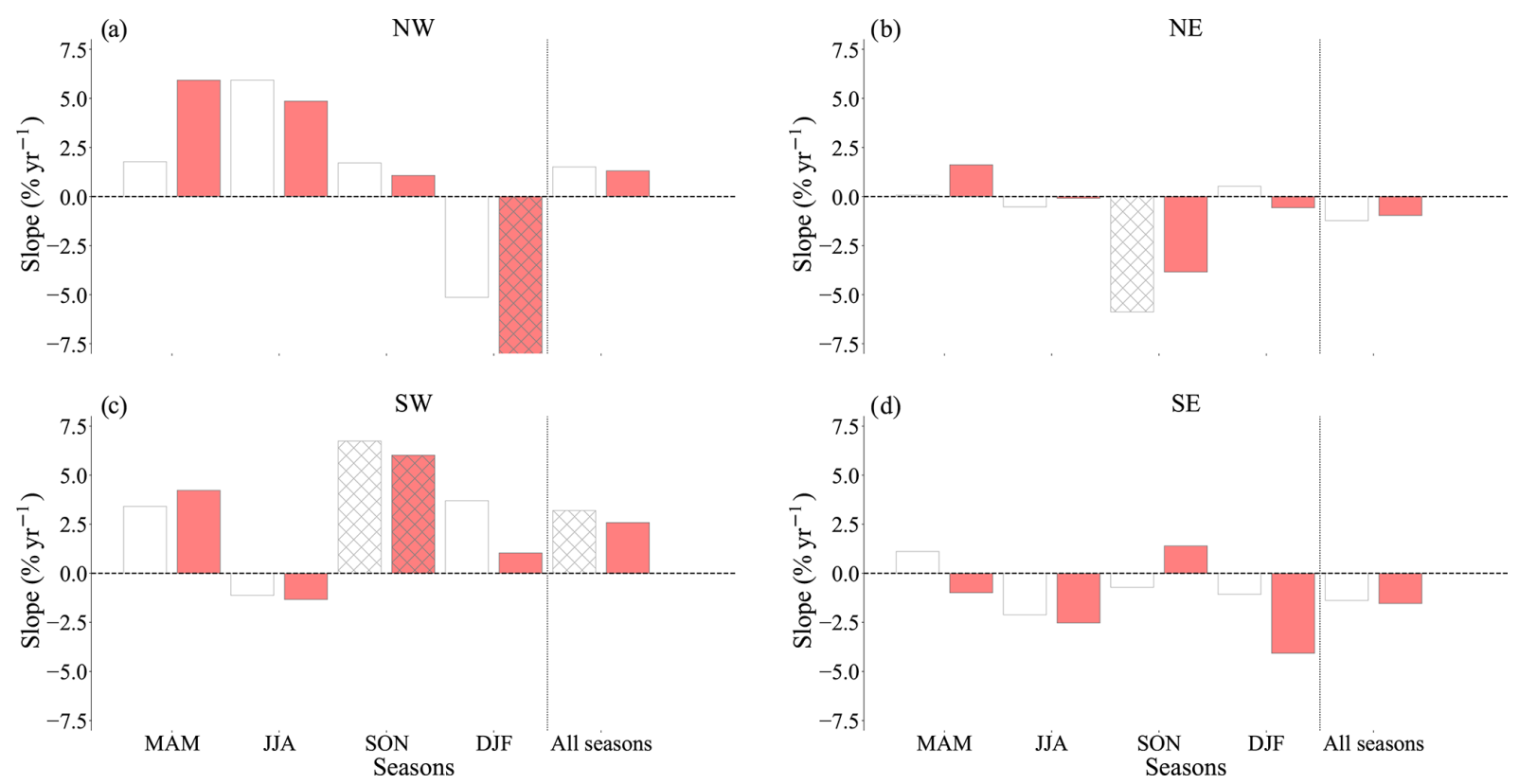

Figure 5. Relative trends in monthly contributions from each respective region: (a) north-west (NW), (b) north-east (NE), (c) south-east (SE), and (d) south-west (SW). The white bar displays the Theil-Sen estimator (TS); the red bar displays log-transformed least mean square (LMS) trends. Cross-hatching denotes trends that are statistically significant at a confidence interval of $95 \%$. The dashed line aids the reader in separating the individual seasonal trends and the trend with all the seasons included.
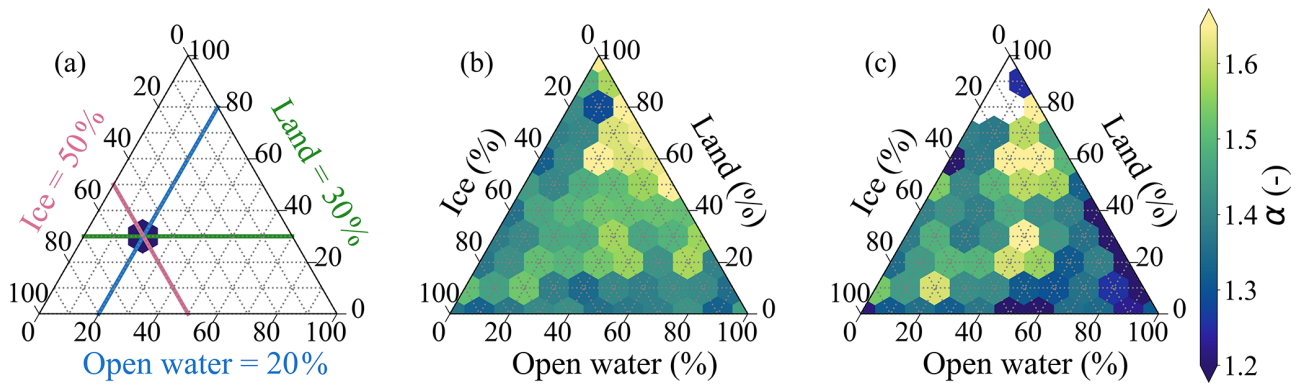

Figure 6. Scattering Ångström exponent $(\alpha)$ as a function of surface type. Each hexbin displays the median of hourly $\alpha$ for that particular combination of surface types (see left schematic). The three vertices display the following surface contributions: $100 \%$ land (top), $100 \%$ open water (right), and $100 \%$ ice (left). The hourly $\alpha$ values are binned according to their proximity to the centre of a hexagon. The surface times are normalised using the time each back trajectory spends within the mixed layer (ML). Certain criteria are placed on the back trajectories: (a) no criteria and (b) $40 \%$ of the $7 \mathrm{~d}$ were spent within the mixed layer. A minimum count of 50 has been placed on the hexbins.

2017), and can contribute to the total amount of scattering. The clear oceanic influence on $\alpha$ (see Fig. 6) suggests that the relative influx of coarse-mode particles is marine in origin and most likely SSA as opposed to coarse-mode-dominated dust from land sources.

Within this work, we show that the increased presence of SSA at ZEP is the result of changes in air circulation patterns, as opposed to the retreat in Arctic sea ice. There is a clear increase in the contribution of SW air masses, in particular in autumn, which coincides with the largest trend in $\alpha$. The trends in $\sigma_{\mathrm{sp}}$ and $\alpha$ in summer can be explained by a greater influx of SSA arriving from the NW, over the Arctic sea ice, during the summer. Despite the continued increase in the expanse of open water in the Arctic Ocean, and the potential for increased SSA production, the effects of retreating sea ice on observations at ZEP were shown to be negligible (Fig. S5 in the Supplement). This study suggests that the growing contribution from western air masses leads to more SSA being transported to ZEP (Fig. 7). The overall effect is that air masses reaching ZEP are becoming more marine dominated. The largest increases in the expanse of summertime open water, within the Arctic Ocean, concern the Beaufort and Chukchi seas. These areas are a considerable distance from ZEP; thus the residence times back trajectories spend over these regions are minimal compared to the combined area that all the back trajectories cover. However, more 


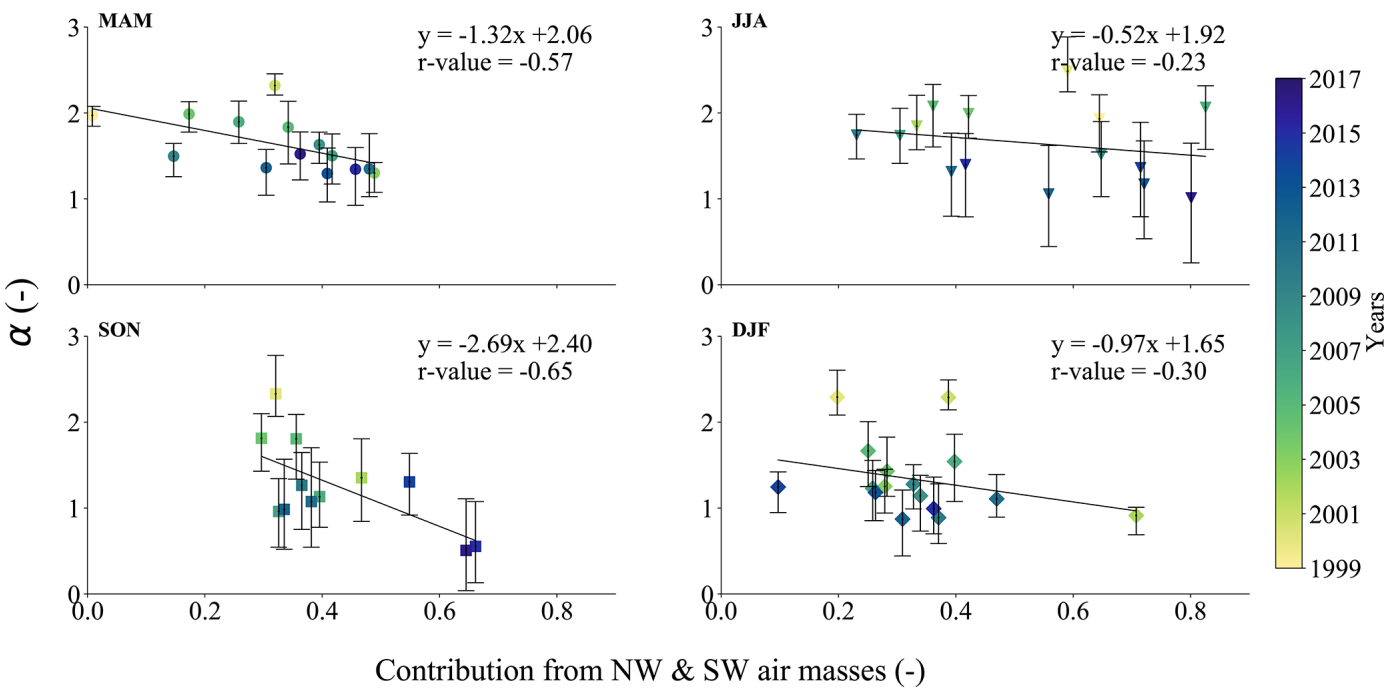

Figure 7. Relationship between the proportion of air masses arriving from the west (i.e. the combination of south-west and north-west regions) with seasonal scattering Ångström exponent $(\alpha)$ medians. The four seasons, namely spring (MAM), summer (JJA), autumn (SON), and winter (DJF), are presented. The error bars denote the length of the 25 th and 75 th percentile values. Note that the number of seasonal medians displayed is larger than the total number of distinct seasons, as winter here is subdivided into the respective years. The ordinary least squares method is applied to the seasonal medians, while the $r$ value denotes the correlation coefficient.

Table 1. Schematic to aid the reader in the discussion related to the observed trends in aerosol light scattering properties and results from the trajectory analysis. Arrows correspond to the sign of the trends. Single arrows are given when the average of the two methods is greater than $1 \%$ or statistically significant. Double arrows display trends where the average trend is more than $2 \%$. The asterisk corresponds to non-statistically significant results from the least squares method (LMS). The brackets correspond to non-statistically significant results from the Mann-Kendall (MK) test. The scattering Ångström exponent uses wavelengths of $\lambda=450$ and $550 \mathrm{~nm}$, while the particle light scattering coefficient is given for the $550 \mathrm{~nm}$ wavelength.

\begin{tabular}{lccccc}
\hline & Spring & Summer & Autumn & Winter & $\begin{array}{c}\text { All } \\
\text { seasons }\end{array}$ \\
\hline$\sigma_{\text {sp }}$ & $\uparrow$ & $\uparrow \uparrow$ & $\uparrow \uparrow$ & $\uparrow \uparrow$ & $\uparrow \uparrow$ \\
$\alpha$ & $\downarrow \downarrow$ & $\downarrow \downarrow$ & $\downarrow \downarrow$ & $\downarrow \downarrow$ & $\downarrow \downarrow$ \\
\hline Open water & $\uparrow \uparrow$ & $\downarrow \downarrow$ & $\uparrow \uparrow$ & - & $\uparrow$ \\
Precipitation & $\uparrow \uparrow$ & - & $\uparrow \uparrow$ & - & $\uparrow \uparrow$ \\
Wind speed & - & - & $\uparrow$ & - & $\uparrow$ \\
\hline NW & $(\uparrow)^{*}$ & $(\uparrow \uparrow)^{*}$ & $(\uparrow)^{*}$ & $(\downarrow \downarrow)$ & $(\uparrow)^{*}$ \\
NE & - & - & $\downarrow \downarrow *$ & - & $(\downarrow)^{*}$ \\
SE & - & $(\downarrow \downarrow)^{*}$ & - & $(\downarrow \downarrow)$ & $(\downarrow)^{*}$ \\
SW & $(\uparrow \uparrow)^{*}$ & $(\downarrow)^{*}$ & $\uparrow \uparrow$ & $(\uparrow \uparrow)^{*}$ & $\uparrow \uparrow *$ \\
\hline
\end{tabular}

work is required to ascertain the exact annual movement of the polar front and whether its location excludes ZEP from any changes in emissions induced by the melting summer sea ice.
The back trajectory analysis offers a plausible partial explanation of the changes in aerosol optical properties observed at ZEP. However, it should be noted that there is unlikely to be any single overarching factor determining the observed trends. Accompanying the changes in air circulation patterns, there is a positive trend in wind speeds along the back trajectories (Figs. 3 and 4). The inverse relationship between wind speeds and $\alpha$ (Woodcock, 1953) suggests that higher wind speeds allow larger particles to be produced and transported to the observatory.

The polar front advances in the winter to include more industrial emissions coming from Eurasia (as showed by the increased NE contribution in Fig. S6 in the Supplement). In the summertime, the polar front retreats, and ZEP is found more often outside of the polar front receiving mainly marine air masses from the Atlantic Ocean (Dall'Osto et al., 2017). The increased contribution from SW air masses in the autumn and winter (Fig. 4) over the 18 years suggests that the time the polar front is residing north of ZEP is increasing; this further signals the observatory's shift from a polar to a marine site. Previous studies have shown that transport through the North Atlantic has become more frequent in the last decades (Mewes and Jacobi, 2019). The long-term increasing trend in the contribution from air masses from the SW in winter and NW in summer is consistent with the findings in Maturilli and Kayser (2017), who have shown that in the winter troposphere, the frequency in wind from northwesterly directions is reduced, and, instead, there is much more frequent wind from southern directions.

The overall changes in air circulation patterns can be tied to regional shifts in weather phenomena. It is well known that 
long-term trends in the North Atlantic Oscillation (NAO) influence long-term trends in Arctic pollution (Stohl, 2006). The Arctic Oscillation (AO) can also be used to describe the same phenomenon as the NAO. The AO index has been shown to be shifted towards more negative anomalies in recent years (Maturilli and Kayser, 2017), which is consistent with the findings in this study. A negative AO increases the amount of meridional transport (south-to-north or vice versa) (Maturilli and Kayser, 2017); the Icelandic low pressure system and the Azores high pressure system are weakened, restricting westerly flow and enabling an increased amount of meridional transport over the North Atlantic.

Other potential explanations for the shift towards large particles exist. The following alternatives are addressed as to whether these trends are the result of any other hypotheses: (1) increased influence of mineral dust in the Arctic; (2) decreases in new particle formation (NPF); (3) decreases in long-range transport and/or local emissions of anthropogenic pollution; or (4) decreases in the scavenging of larger particles due to changes in the rates of wet deposition.

Mineral dust, arising from deglaciation in the Arctic, is another coarse-mode aerosol with the potential to be observed at ZEP. However, it is well established that SSA is the most abundant coarse-mode aerosol at ZEP (Weinbruch et al., 2012). The clear open water dependency of $\alpha$ (see Fig. 6) suggests the changes are a result of marine influences, thus negating (1). Ultrafine particles $(<100 \mathrm{~nm})$ produced via NPF are considered to contribute a negligible amount to the total aerosol light scattering. Furthermore, NPF events at ZEP have been shown to be anti-correlated with sea ice extent (Dall'Osto et al., 2017); thus (2) is not considered. Anthropogenic pollution, which is either transported up to the Arctic or produced locally, is typically dominated by accumulation-mode aerosol particles and thus exhibits higher $\alpha$ values. If (3) is assumed and also that there is no increase in the contribution from coarse-mode aerosol, it is difficult to explain the observed increasing trend in $\sigma_{\mathrm{sp}}$. The measurements in this study, however, cannot be used to demonstrate a reduction in anthropogenic pollution at ZEP. However, previous studies have reported reductions in elemental black carbon (BC) at ZEP (Stone et al., 2014; Eleftheriadis et al., 2009; Hirdman et al., 2010), notable given the increase in $\mathrm{BC}$ emission inventories in the past decade (Ohara et al., 2007). Hirdman et al. (2010) also present reductions in measured total sulfate concentrations at ZEP. It should be noted that Hirdman et al. (2010) conclude that about $4.9 \%$ and $0.3 \%$ of the reductions in $\mathrm{BC}$ and sulfate respectively at ZEP can be explained by circulation changes within the time period (1990-2009). Higher median $\alpha$ values for the air masses arriving from the north-east and south-east are observed (Fig. S7 in the Supplement). These air masses, where a considerable amount of Eurasian pollution originates from, have decreased in their relative contribution. The influence of wet deposition on Arctic aerosol requires a thorough analysis. However, the trend in precipitation from arriving back trajectories is increasing (Fig. 4c), as wetter air masses from the south-west arrive at the observatory. The increase in precipitation suggests that (4) is unlikely to be the reason for the shift to more coarse-mode particles. Dall'Osto et al. (2017) show that NPF events are linked to the retreat in Arctic sea ice; ultrafine particles $(<100 \mathrm{~nm})$ are shown to be associated with air masses travelling over open water and sea ice. In this study, SSA is linked to air masses traversing over open water; however, the overall mechanism that is ascribed to the observed aerosol trends is changes in air mass contributions.

\section{Conclusion}

Aerosol composition at ZEP has undergone significant changes over the last 2 decades, manifesting in a clear shift of aerosol light scattering properties. The statistically significant increasing trend in $\sigma_{\mathrm{sp}}$ of $\sim 2.6 \% \mathrm{yr}^{-1}$ to $2.9 \% \mathrm{yr}^{-1}$, combined with a statistically significant decreasing trend in $\alpha$ of around $-4.9 \% \mathrm{yr}^{-1}$ to $-6.5 \% \mathrm{yr}^{-1}$, demonstrates that aerosol observed at ZEP has become more dominated by coarse-mode particles over time, which in turn contribute a greater proportion to the scattering of light. There is a clear open water dependency on $\alpha$, suggesting that the increasing trend is a result of marine influences leading to increased transport of SSA to the site. The strong decrease of Arctic sea ice over the last decades, leading to more open water, is, however, not the main reason for the increased contribution of SSA. Here, we demonstrate that the growing marine influence originates from the increasing time back trajectories spend over the open water, particularly south-west of Svalbard. As such, the changes in air circulation patterns have resulted in a characteristic shift of ZEP, from an Arctic towards a more marine-dominated site.

ZEP is a site that requires detailed analysis, given the significance and magnitude of the observed trends. The results in this study suggest that climate-related changes are influencing the transportation of aerosol particles in and to the Arctic region, as well as the processing and sources of particles. It is important to note that the results are site dependent and that no general conclusions for the entire Arctic can be made.

Data availability. The data of this study are available in the Bolin Centre for Climate Research Database at https://doi.org/10.17043/zeppelin-aerosol-light-scattering (HeslinRees et al., 2020).

Supplement. The supplement related to this article is available online at: https://doi.org/10.5194/acp-20-13671-2020-supplement.

Author contributions. DHR performed data analysis and wrote the manuscript together with PZ, with input from all co-authors. PT per- 
formed trajectory calculations. HCH and JS were part of the start-up and operation of the long-term measurements. All authors read and commented on the manuscript.

Competing interests. Paul Zieger and Radovan Krejci are acting as co-editors of Atmospheric Chemistry and Physics. No further competing interests are applicable.

Acknowledgements. We would like to thank research engineers Birgitta Noone, Tabea Henning, and Ondrej Tesar from ACES and the staff from the Norwegian Polar Institute (NPI) for their on-site support. NPI is also acknowledged for substantial long-term support in maintaining the measurements at the Zeppelin Observatory. We thank the Norwegian Institute for Air Research (NILU) for providing the ambient meteorological data and for maintaining the EBAS database. We thank Elisabeth Andrews (NOAA/CIRES, USA) for support and guidance.

Financial support. This research has been supported by the long-term support of the Swedish EPA's (Naturvårdsverket) environmental monitoring programme (Miljöövervakning) and the Knut and Alice Wallenberg Foundation within the ACAS project (Arctic Climate Across Scales, project no. 2016.0024).

The article processing charges for this open-access publication were covered by Stockholm University.

Review statement. This paper was edited by Markus Petters and reviewed by two anonymous referees.

\section{References}

Anderson, T. L. and Ogren, J. A.: Determining aerosol radiative properties using the TSI 3563 integrating nephelometer, Aerosol Sci. Tech., 29, 57-69, 1998.

Anderson, T. L., Covert, D., Marshall, S., Laucks, M., Charlson, R., Waggoner, A., Ogren, J., Caldow, R., Holm, R., Quant, F., Sem, G. J., Wiedensohler, A., Ahlquist, N. A., and Bates, T. S.: Performance characteristics of a high-sensitivity, three-wavelength, total scatter/backscatter nephelometer, J. Atmos. Ocean. Tech., 13, 967-986, 1996.

Ångström, A.: On the atmospheric transmission of sun radiation and on dust in the air, Geogr. Ann., 11, 156-166, 1929.

Asmi, A., Collaud Coen, M., Ogren, J. A., Andrews, E., Sheridan, P., Jefferson, A., Weingartner, E., Baltensperger, U., Bukowiecki, N., Lihavainen, H., Kivekäs, N., Asmi, E., Aalto, P. P., Kulmala, M., Wiedensohler, A., Birmili, W., Hamed, A., O'Dowd, C., G Jennings, S., Weller, R., Flentje, H., Fjaeraa, A. M., Fiebig, M., Myhre, C. L., Hallar, A. G., Swietlicki, E., Kristensson, A., and Laj, P.: Aerosol decadal trends - Part 2: In-situ aerosol particle number concentrations at GAW and ACTRIS stations, Atmos. Chem. Phys., 13, 895-916, https://doi.org/10.5194/acp-13-8952013, 2013.
Browse, J., Carslaw, K. S., Mann, G. W., Birch, C. E., Arnold, S. R., and Leck, C.: The complex response of Arctic aerosol to sea-ice retreat, Atmos. Chem. Phys., 14, 7543-7557, https://doi.org/10.5194/acp-14-7543-2014, 2014.

Cohen, J., Screen, J. A., Furtado, J. C., Barlow, M., Whittleston, D., Coumou, D., Francis, J., Dethloff, K., Entekhabi, D., Overland, J., and Jones, J.: Recent Arctic amplification and extreme midlatitude weather, Nat. Geosci., 7, 627-637, 2014.

Collaud Coen, M., Weingartner, E., Nyeki, S., Cozic, J., Henning, S., Verheggen, B., Gehrig, R., and Baltensperger, U.: Long-term trend analysis of aerosol variables at the highalpine site Jungfraujoch, J. Geophys. Res. Atmos., 112, D13213, https://doi.org/10.1029/2006JD007995, 2007.

Collaud Coen, M., Andrews, E., Asmi, A., Baltensperger, U., Bukowiecki, N., Day, D., Fiebig, M., Fjaeraa, A. M., Flentje, H., Hyvärinen, A., Jefferson, A., Jennings, S. G., Kouvarakis, G., Lihavainen, H., Lund Myhre, C., Malm, W. C., Mihapopoulos, N., Molenar, J. V., O’Dowd, C., Ogren, J. A., Schichtel, B. A., Sheridan, P., Virkkula, A., Weingartner, E., Weller, R., and Laj, P.: Aerosol decadal trends - Part 1: In-situ optical measurements at GAW and IMPROVE stations, Atmos. Chem. Phys., 13, 869894, https://doi.org/10.5194/acp-13-869-2013, 2013.

Collaud Coen, M., Andrews, E., Alastuey, A., Arsov, T. P., Backman, J., Brem, B. T., Bukowiecki, N., Couret, C., Eleftheriadis, K., Flentje, H., Fiebig, M., Gysel-Beer, M., Hand, J. L., Hoffer, A., Hooda, R., Hueglin, C., Joubert, W., Keywood, M., Kim, J. E., Kim, S.-W., Labuschagne, C., Lin, N.-H., Lin, Y., Lund Myhre, C., Luoma, K., Lyamani, H., Marinoni, A., MayolBracero, O. L., Mihalopoulos, N., Pandolfi, M., Prats, N., Prenni, A. J., Putaud, J.-P., Ries, L., Reisen, F., Sellegri, K., Sharma, S., Sheridan, P., Sherman, J. P., Sun, J., Titos, G., Torres, E., Tuch, T., Weller, R., Wiedensohler, A., Zieger, P., and Laj, P.: Multidecadal trend analysis of in situ aerosol radiative properties around the world, Atmos. Chem. Phys., 20, 8867-8908, https://doi.org/10.5194/acp-20-8867-2020, 2020.

Dai, A., Luo, D., Song, M., and Liu, J.: Arctic amplification is caused by sea-ice loss under increasing $\mathrm{CO}_{2}$, Nat. Commun., 10, $1-13,2019$.

Dall'Osto, M., Beddows, D., Tunved, P., Krejci, R., Ström, J., Hansson, H.-C., Yoon, Y., Park, K.-T., Becagli, S., Udisti, R., Onasch, T., O’Dowd, C. D., Simó, R., and Harrison, R. M.: Arctic sea ice melt leads to atmospheric new particle formation, Sci. Rep., 7, 3318, https://doi.org/10.1038/s41598-017-03328-1, 2017.

De Leeuw, G., Andreas, E. L., Anguelova, M. D., Fairall, C., Lewis, E. R., O'Dowd, C., Schulz, M., and Schwartz, S. E.: Production flux of sea spray aerosol, Rev. Geophys., 49, RG2001, https://doi.org/10.1029/2010RG000349, 2011.

Draxler, R. R. and Hess, G.: An overview of the HYSPLIT_4 modelling system for trajectories, Aust. Meteorol. Mag., 47, 295308, 1998.

Eleftheriadis, K., Vratolis, S., and Nyeki, S.: Aerosol black carbon in the European Arctic: measurements at Zeppelin station, Ny-Ålesund, Svalbard from 1998-2007, Geophys. Res. Lett., 36, L02809, https://doi.org/10.1029/2008GL035741, 2009.

Fetterer, F., Knowles, K., Meier, W., Savoie, M., and Windnagel, A.: Sea ice index, version 2, NSIDC: National Snow and Ice Data Center, Boulder, Colorado USA, 2016.

Francis, J. A., Vavrus, S. J., and Cohen, J.: Amplified Arctic warming and mid-latitude weather: new perspectives on emerging 
connections, Wiley Interdiscip. Rev. Clim. Change, 8, e474, https://doi.org/10.1002/wcc.474, 2017.

Freud, E., Krejci, R., Tunved, P., Leaitch, R., Nguyen, Q. T., Massling, A., Skov, H., and Barrie, L.: Pan-Arctic aerosol number size distributions: seasonality and transport patterns, Atmos. Chem. Phys., 17, 8101-8128, https://doi.org/10.5194/acp17-8101-2017, 2017.

Fyfe, J. C., Von Salzen, K., Gillett, N. P., Arora, V. K., Flato, G. M., and McConnell, J. R.: One hundred years of Arctic surface temperature variation due to anthropogenic influence, Sci. Rep., 3, 2645, https://doi.org/10.1038/srep02645, 2013.

Garrett, T. J. and Verzella, L. L.: Looking back: An evolving history of Arctic aerosols, B. Am. Meteorol. Soc., 89, 299-302, 2008.

Gilbert, R. O.: Statistical methods for environmental pollution monitoring, John Wiley \& Sons, New York, USA, 1987.

Hansen, J., Rossow, W., Carlson, B., Lacis, A., Travis, L., Del Genio, A., Fung, I., Cairns, B., Mishchenko, M., and Sato, M.: Low-cost long-term monitoring of global climate forcings and feedbacks, Climatic Change, 31, 247-271, https://doi.org/10.1007/BF01095149, 1995.

Haywood, J. and Shine, K.: The effect of anthropogenic sulfate and soot aerosol on the clear sky planetary radiation budget, Geophys. Res. Lett., 22, 603-606, https://doi.org/10.1029/95GL00075, 1995.

Heintzenberg, J.: Size-segregated measurements of particulate elemental carbon and aerosol light absorption at remote Arctic locations, Atmos. Environ., 16, 2461-2469, 1982.

Heslin-Rees, D., Burgos, M., Hansson, H. C., Krejci, R., Ström, J., Tunved, P., and Zieger, P.: Aerosol light scattering properties at Zeppelin Observatory, Svalbard, 1999-2016, combined with back trajectory analysis parameters, Dataset version 1.0. Bolin Centre Database, https://doi.org/10.17043/zeppelinaerosol-light-scattering, 2020.

Hirdman, D., Burkhart, J. F., Sodemann, H., Eckhardt, S., Jefferson, A., Quinn, P. K., Sharma, S., Ström, J., and Stohl, A.: Long-term trends of black carbon and sulphate aerosol in the Arctic: changes in atmospheric transport and source region emissions, Atmos. Chem. Phys., 10, 9351-9368, https://doi.org/10.5194/acp-109351-2010, 2010.

Hirsch, R. M., Slack, J. R., and Smith, R. A.: Techniques of trend analysis for monthly water quality data, Water Resour. Res., 18, 107-121, 1982.

IPCC: Climate Change 2013: The Physical Science Basis, Contribution of Working Group I to the Fifth Assessment Report of the Intergovernmental Panel on Climate Change, edited by: Stocker, T. F., Qin, D., Plattner, G.-K., Tignor, M., Allen, S. K., Boschung, J., Nauels, A., Xia, Y., Bex, V., and Midgley, P. M., Cambridge University Press, Cambridge, UK and New York, NY, USA, 1535 pp., 2013.

Jung, C. H., Yoon, Y. J., Kang, H. J., Gim, Y., Lee, B. Y., Ström, J., Krejci, R., and Tunved, P.: The seasonal characteristics of cloud condensation nuclei $(\mathrm{CCN})$ in the arctic lower troposphere, Tellus B, 70, 1-13, 2018.

Kulkarni, A. and von Storch, H.: Monte Carlo experiments on the effect of serial correlation on the Mann-Kendall test of trend, Meteorol. Z., 4, 82-85, 1995.

Lee, M.-Y., Hong, C.-C., and Hsu, H.-H.: Compounding effects of warm sea surface temperature and reduced sea ice on the extreme circulation over the extratropical North Pacific and North Amer- ica during the 2013-2014 boreal winter, Geophys. Res. Lett., 42, 1612-1618, 2015.

Lewis, E. and Schwartz, S. E.: Sea salt aerosol production, Mechanisms, methods, measurements, and models, American Geophysical Union, Washington, D.C., USA, 2004.

Maturilli, M. and Kayser, M.: Arctic warming, moisture increase and circulation changes observed in the Ny-Ålesund homogenized radiosonde record, Theor. Appl. Climatol., 130, 1-17, 2017.

Meredith, M., Sommerkorn, M., Cassotta, S., Derksen, C., Ekaykin, A., Hollowed, A., Kofinas, G., Mackintosh, A., MelbourneThomas, J., Muelbert, M. M. C., Ottersen, G., Pritchard, H., and Schuur, E. A. G.: Polar Regions, in: IPCC Special Report on the Ocean and Cryosphere in a Changing Climate, edited by: Pörtner, H.-O., Roberts, D. C., Masson-Delmotte, V., Zhai, P., Tignor, M., Poloczanska, E., Mintenbeck, K., Alegría, A., Nicolai, M., Okem, A., Petzold, J., Rama, B., and Weyer, N. M., in press, 2020.

Mewes, D. and Jacobi, C.: Heat transport pathways into the Arctic and their connections to surface air temperatures, Atmos. Chem. Phys., 19, 3927-3937, https://doi.org/10.5194/acp-193927-2019, 2019.

Navarro, J. A., Varma, V., Riipinen, I., Seland, Ø., Kirkevåg, A., Struthers, H., Iversen, T., Hansson, H.-C., and Ekman, A. M.: Amplification of Arctic warming by past air pollution reductions in Europe, Nat. Geosci., 9, 277-281, 2016.

Nordli, Ø., Przybylak, R., Ogilvie, A. E., and Isaksen, K.: Longterm temperature trends and variability on Spitsbergen: the extended Svalbard Airport temperature series, 1898-2012, Polar Res., 33, 21349, https://doi.org/10.3402/polar.v33.21349, 2014.

O'Dowd, C. D. and De Leeuw, G.: Marine aerosol production: a review of the current knowledge, Philos. T. Roy. Soc. A, 365, 1753-1774, 2007.

Ohara, T., Akimoto, H., Kurokawa, J., Horii, N., Yamaji, K., Yan, X., and Hayasaka, T.: An Asian emission inventory of anthropogenic emission sources for the period 1980-2020, Atmos. Chem. Phys., 7, 4419-4444, https://doi.org/10.5194/acp-7-44192007, 2007.

Overland, J. E. and Wang, M.: Recent extreme Arctic temperatures are due to a split polar vortex, J. Climate, 29, 5609-5616, 2016.

Pandolfi, M., Alados-Arboledas, L., Alastuey, A., Andrade, M., Angelov, C., Artiñano, B., Backman, J., Baltensperger, U., Bonasoni, P., Bukowiecki, N., Collaud Coen, M., Conil, S., Coz, E., Crenn, V., Dudoitis, V., Ealo, M., Eleftheriadis, K., Favez, O., Fetfatzis, P., Fiebig, M., Flentje, H., Ginot, P., Gysel, M., Henzing, B., Hoffer, A., Holubova Smejkalova, A., Kalapov, I., Kalivitis, N., Kouvarakis, G., Kristensson, A., Kulmala, M., Lihavainen, H., Lunder, C., Luoma, K., Lyamani, H., Marinoni, A., Mihalopoulos, N., Moerman, M., Nicolas, J., O’Dowd, C., Petäjä, T., Petit, J.-E., Pichon, J. M., Prokopciuk, N., Putaud, J.P., Rodríguez, S., Sciare, J., Sellegri, K., Swietlicki, E., Titos, G., Tuch, T., Tunved, P., Ulevicius, V., Vaishya, A., Vana, M., Virkkula, A., Vratolis, S., Weingartner, E., Wiedensohler, A., and Laj, P.: A European aerosol phenomenology - 6: scattering properties of atmospheric aerosol particles from 28 ACTRIS sites, Atmos. Chem. Phys., 18, 7877-7911, https://doi.org/10.5194/acp18-7877-2018, 2018. 
Park, H.-S., Lee, S., Son, S.-W., Feldstein, S. B., and Kosaka, Y.: The impact of poleward moisture and sensible heat flux on Arctic winter sea ice variability, J. Climate, 28, 5030-5040, 2015.

Perovich, D., Meier, W., Tschudi, M., Farrell, S., Hendricks, S., Gerland, S., Haas, C., Krumpen, T., Polashenski, C., Ricker, R., and Webster, M.: Sea Ice, in: Arctic Report Card 2018, available at: http://www.arctic.noaa.gov/Report-Card (last access: 30 April 2019), 2018.

Pithan, F., Svensson, G., Caballero, R., Chechin, D., Cronin, T. W., Ekman, A. M., Neggers, R., Shupe, M. D., Solomon, A., Tjernström, M., and Wendisch, M.: Role of air-mass transformations in exchange between the Arctic and mid-latitudes, Nat. Geosci., 11, 805-812, 2018.

Quinn, P., Shaw, G., Andrews, E., Dutton, E., Ruoho-Airola, T., and Gong, S.: Arctic haze: current trends and knowledge gaps, Tellus B, 59, 99-114, 2007.

Rayner, N., Parker, D. E., Horton, E., Folland, C. K., Alexander, L. V., Rowell, D., Kent, E., and Kaplan, A.: Global analyses of sea surface temperature, sea ice, and night marine air temperature since the late nineteenth century, J. Geophys. Res.-Atmos., 108, 4407, https://doi.org/10.1029/2002JD002670, 2003.

Schmeisser, L., Andrews, E., Ogren, J. A., Sheridan, P., Jefferson, A., Sharma, S., Kim, J. E., Sherman, J. P., Sorribas, M., Kalapov, I., Arsov, T., Angelov, C., Mayol-Bracero, O. L., Labuschagne, C., Kim, S.-W., Hoffer, A., Lin, N.-H., Chia, H.-P., Bergin, M., Sun, J., Liu, P., and Wu, H.: Classifying aerosol type using in situ surface spectral aerosol optical properties, Atmos. Chem. Phys., 17, 12097-12120, https://doi.org/10.5194/acp-17-120972017, 2017.

Schmeisser, L., Backman, J., Ogren, J. A., Andrews, E., Asmi, E., Starkweather, S., Uttal, T., Fiebig, M., Sharma, S., Eleftheriadis, K., Vratolis, S., Bergin, M., Tunved, P., and Jefferson, A.: Seasonality of aerosol optical properties in the Arctic, Atmos. Chem. Phys., 18, 11599-11622, https://doi.org/10.5194/acp-18-115992018, 2018.

Schuster, G. L., Dubovik, O., and Holben, B. N.: Angstrom exponent and bimodal aerosol size distributions, J. Geophys. Res.Atmos., 111, D07207, https://doi.org/10.1029/2005JD006328, 2006.

Schweiger, A. J., Lindsay, R. W., Vavrus, S., and Francis, J. A.: Relationships between Arctic sea ice and clouds during autumn, J. Climate, 21, 4799-4810, 2008.

Screen, J. A. and Simmonds, I.: The central role of diminishing sea ice in recent Arctic temperature amplification, Nature, 464, 1334-1337, 2010.

Seinfeld, J. and Pandis, S.: Atmospheric Chemistry and Physics, A Wiley-Inter Science Publication, John Wiley \& Sons Inc, New York, USA, 2006.

Sen, P. K.: Estimates of the regression coefficient based on Kendall's tau, J. Am. Stat. Assoc., 63, 1379-1389, 1968.

Serreze, M. C. and Barry, R. G.: Processes and impacts of Arctic amplification: A research synthesis, Global Planet. Change, 77, 85-96, 2011.

Shaw, G. E.: The Arctic haze phenomenon, B. Am. Meteorol. Soc., 76, 2403-2414, 1995.

Sokolik, I. N., Curry, J., and Radionov, V.: Interactions of Arctic aerosols with land-cover and land-use changes in Northern Eurasia and their role in the Arctic climate system, in: Eurasian Arctic land cover and land use in a changing climate, Springer, Dor- drecht, the Netherlands, 237-268, https://doi.org/10.1007/97890-481-9118-5_10, 2010.

Stohl, A.: Characteristics of atmospheric transport into the Arctic troposphere, J. Geophys. Res.-Atmos., 111, D11306, https://doi.org/10.1029/2005JD006888, 2006.

Stone, R. S., Sharma, S., Herber, A., Eleftheriadis, K., and Nelson, D. W.: A characterization of Arctic aerosols on the basis of aerosol optical depth and black carbon measurements, Elementa, 2, 000027, https://doi.org/10.12952/journal.elementa.000027, 2014.

Stroeve, J. and Meier, W.: Sea ice trends and climatologies from SMMR and SSM/I-SSMIS, Version 1, NASA National Snow and Ice Data Center Distributed Active Archive Center, Boulder, Colorado USA, 2003.

Ström, J., Umegård, J., Tørseth, K., Tunved, P., Hansson, H.-C., Holmén, K., Wismann, V., Herber, A., and König-Langlo, G.: One year of particle size distribution and aerosol chemical composition measurements at the Zeppelin Station, Svalbard, March 2000-March 2001, Phys. Chem. Earth Pt. A/B/C, 28, 11811190, 2003.

Struthers, H., Ekman, A. M. L., Glantz, P., Iversen, T., Kirkevåg, A., Mårtensson, E. M., Seland, Ø., and Nilsson, E. D.: The effect of sea ice loss on sea salt aerosol concentrations and the radiative balance in the Arctic, Atmos. Chem. Phys., 11, 3459-3477, https://doi.org/10.5194/acp-11-3459-2011, 2011

Tunved, P., Ström, J., and Krejci, R.: Arctic aerosol life cycle: linking aerosol size distributions observed between 2000 and 2010 with air mass transport and precipitation at Zeppelin station, Ny-Ålesund, Svalbard, Atmos. Chem. Phys., 13, 3643-3660, https://doi.org/10.5194/acp-13-3643-2013, 2013.

Valero, F. P., Ackerman, T. P., and Gore, W. J.: The effects of the Arctic haze as determined from airborne radiometric measurements during AGASP II, J. Atmos. Chem., 9, 225-244, 1989.

Virtanen, P., Gommers, R., Oliphant, T. E., Haberland, M., Reddy, T., Cournapeau, D., Burovski, E., Peterson, P., Weckesser, W., Bright, J., van der Walt, S. J., Brett, M., Wilson, J., Millman, K. J., Mayorov, N., Nelson, A. R. J., Jones, E., Kern, R., Larson, E., Carey, C. J., Polat, İ., Feng, Y., Moore, E. W., VanderPlas, J., Laxalde, D., Perktold, J., Cimrman, R., Henriksen, I., Quintero, E. A., Harris, C. R., Archibald, A. M., Ribeiro, A. H., Pedregosa, F., van Mulbregt, P., and SciPy 1.0 Contributors: SciPy 1.0: Fundamental Algorithms for Scientific Computing in Python, Nature Methods, 17, 261-272, https://doi.org/10.1038/s41592-0190686-2, 2020.

Warneke, C., Bahreini, R., Brioude, J., Brock, C., De Gouw, J., Fahey, D., Froyd, K., Holloway, J., Middlebrook, A., Miller, L., Montzka, S., Murphy, D. M., Peischl, J., Ryerson, T. B., Schwarz, J. P., Spackman, J. R., and Veres, P.: Biomass burning in Siberia and Kazakhstan as an important source for haze over the Alaskan Arctic in April 2008, Geophys. Res. Lett., 36, L02813, https://doi.org/10.1029/2008GL036194, 2009.

Weinbruch, S., Wiesemann, D., Ebert, M., Schütze, K., Kallenborn, R., and Ström, J.: Chemical composition and sources of aerosol particles at Zeppelin Mountain (Ny Ålesund, Svalbard): An electron microscopy study, Atmos. Environ., 49, 142-150, 2012.

Weingartner, E., Nyeki, S., and Baltensperger, U.: Seasonal and diurnal variation of aerosol size distributions $(10<D<750 \mathrm{~nm})$ at a high-alpine site (Jungfraujoch 
$3580 \mathrm{~m}$ asl), J. Geophys. Res.-Atmos., 104, 26809-26820, https://doi.org/10.1029/1999JD900170, 1999.

Willis, M. D., Leaitch, W. R., and Abbatt, J. P.: Processes controlling the composition and abundance of Arctic aerosol, Rev. Geophys., 56, 621-671, 2018.

WMO: WMO/GAW Aerosol Measurement procedures guidelines and recommendations, Tech. Rep. 227, Geneva, Switzerland, 2016.

Woodcock, A. H.: Salt nuclei in marine air as a function of altitude and wind force, J. Meteorol., 10, 362-371, 1953.

Yue, S., Pilon, P., Phinney, B., and Cavadias, G.: The influence of autocorrelation on the ability to detect trend in hydrological series, Hydrol. Process., 16, 1807-1829, 2002.
Zieger, P., Fierz-Schmidhauser, R., Gysel, M., Ström, J., Henne, S., Yttri, K. E., Baltensperger, U., and Weingartner, E.: Effects of relative humidity on aerosol light scattering in the Arctic, Atmos. Chem. Phys., 10, 3875-3890, https://doi.org/10.5194/acp10-3875-2010, 2010.

Zieger, P., Fierz-Schmidhauser, R., Weingartner, E., and Baltensperger, U.: Effects of relative humidity on aerosol light scattering: results from different European sites, Atmos. Chem. Phys., 13, 10609-10631, https://doi.org/10.5194/acp-13-106092013, 2013. 